\title{
Fractional-Order System Modeling and its Applications
}

www.jestr.org

\author{
Kajal Kothari*, Utkal Mehta and Ravneel Prasad
}

School of Engineering and Physics, The University of the South Pacific, Laucala campus, Fiji.

Received 17 July 2019; Accepted 14 December 2019

\begin{abstract}
In order to control or operate any system in a closed-loop, it is important to know its behavior in the form of mathematical models. In the last two decades, a fractional-order model has received more attention in system identification instead of classical integer-order model transfer function. Literature shows recently that some techniques on fractional calculus and fractional-order models have been presenting valuable contributions to real-world processes and achieved better results. Such new developments have impelled research into extensions of the classical identification techniques to advanced fields of science and engineering. This article surveys the recent methods in the field and other related challenges to implement the fractional-order derivatives and miss-matching with conventional science. The comprehensive discussion on available literature would help the readers to grasp the concept of fractional-order modeling and can facilitate future investigations. One can anticipate manifesting recent advances in fractional-order modeling in this paper and unlocking more opportunities for research.
\end{abstract}

Keywords: Fractional-order systems, Modeling of LTI systems, Identification, SISO, MIMO

\section{Introduction}

Though the concept of fractional calculus (FC) is not new in mathematics, its applications in various science and engineering fields are making it more interesting to researchers [1]. In nature, most real phenomena exhibit arbitrary value of order which can be better characterized by fractional (positive real) differential equations. Say for example, semi-infinite lossy $(\mathrm{RC})$ transmission line, viscoelasticity, dielectric polarization, colored noise, diffusion of heat into semi-infinite solid, electrode-electrolyte polarization, boundary layer effects in ducts, electromagnetic waves and many more. This could be the reason for going towards fractional-order modeling. Already literature on fractional calculus were discussed for possibility in science fields, for instance, bioengineering, physics, control system, signal processing, robotics, chemistry, chaos theory, biology and physiology [2]. It is well adopted by now that integro-differential equation, with an arbitrary order of operation, facilitates additional flexibility and an extra degree of freedom even with firstorder or lower-order models. In general, such transfer function model is called a fractional-order model (FOM) which is an important consideration to determine the exact characteristics of real-time behavior.

This article collects a broad variety of fractional-order modeling techniques, especially focusing on handling realorder derivatives using complicated algorithms. Therefore, one can anticipate to manifest recent advances in fractionalorder modeling and unlock more opportunities to research.

The remainder of the paper is outlined as follows. The fundamentals of FC and fractional-order transfer function are described in Section 2. The following Section 3 presents

*E-mail address: s11151029@student.usp.ac.fi

ISSN: 1791-2377 @ 2019 School of Science, IHU. All rights reserved.

doi:10.25103/iestr.126.01 various techniques that significantly contributed to FOM. The technological superiority has been discussed through example study in Section 4 and then followed by applications and implementation issues presented in Section 5. Finally, the key points are summarized in Section 6.

\section{Fractional Systems and Mathematical Background}

A general single-input single-output (SISO) system is characterized by fractional-order differential equation as,

$$
\begin{aligned}
& a_{n} D_{t}^{\alpha_{n}} y(t)+a_{n-1} D_{t}^{\alpha_{n-1}} y(t)+\ldots \ldots+a_{0} D_{t}^{\alpha_{0}} y(t)= \\
& =b_{m} D_{t}^{\beta_{m}} u(t)+b_{m-1} D_{t}^{\beta_{m-1}} u(t)+\ldots \ldots+b_{0} D_{t}^{\beta_{0}} u(t)
\end{aligned}
$$

where $\left(a_{i}, b_{j}\right) \in R^{2}$ and $\left(\alpha_{i}, \beta_{j}\right) \in R_{+}^{2}$ with $u(t)$ being input to the system and $y(t)$ being output signals which are differentiated to arbitrary positive real orders.

A real or non-integer order derivative in Eq. (1) can be expressed by its operator in a simple form as,

$$
{ }_{c} D_{t}^{\lambda}=\left(\frac{d^{\lambda}}{d t^{\lambda}}\right)
$$

where $c$ and $t$ are the bounds of the operation and $\lambda(\lambda \in R)$ is the real order whose value depicts the nature of operation. Basically, a positive value of $\lambda$ exhibits fractional differentiation and negative value exhibits fractional integration ${ }_{c} I_{t}^{\lambda}$. When $\lambda=0$ yields constant value, therefore, ${ }_{c} D_{t}^{\lambda}=1$.

Applying Laplace transform in Eq. (1) and generalizing the transfer function gives: 
$p(s)=\frac{Y(s)}{U(s)}=\frac{b_{m} s^{\beta_{m}}+b_{m-1} s^{\beta_{m-1}}+\ldots+b_{0} s^{\beta_{0}}}{a_{n} s^{\alpha_{n}}+a_{n-1} s^{\alpha_{n-1}}+\ldots+a_{0} s^{\alpha_{0}}}$

where the static gain of the system is given by $k=b_{0} / a_{0}$ if $\alpha_{0}=\beta_{0}=1$.
There exist multiple definitions to characterize fractional operator. All definitions have different representations but exhibit similar characteristics with some specific conditions. Among them, the Riemann-Liouville (R-L), the GrunwaldLetnikov (GL) and the Caputo definitions are very popular and commonly found in literature [2]. These definitions are outlined in Table. 1.

Table 1. Well-known FC definitions

\begin{tabular}{|c|c|}
\hline Definitions & Fractional derivative \\
\hline R-L & ${ }_{c} \mathscr{D}_{t}^{\lambda} x(t)=\frac{1}{\Gamma(n-\lambda)}\left(\frac{d}{d t}\right)^{n} \int^{t} \frac{x(\tau)}{(t-\tau)^{\lambda+1-n}} d \tau$ \\
\hline $\begin{array}{l}\text { G-L } \\
\text { Caputo }\end{array}$ & $\begin{array}{l}{ }_{c} \mathscr{D}_{t}^{\lambda} x(t)=\lim _{h \rightarrow 0} \frac{1}{h^{\lambda}} \sum_{j=0}^{[t-c] / h^{c}}\left(\begin{array}{c}q \\
j\end{array}\right) x(t-j h) \\
{ }_{c} \mathscr{D}_{t}^{\lambda} x(t)=\frac{1}{\Gamma(n-\lambda)} \int_{0}^{t} \frac{x^{(n)}(\tau)}{(t-\tau)^{\lambda-n+1}} d \tau\end{array}$ \\
\hline
\end{tabular}

In Table. $1, \Gamma$ denotes Euler's gamma function, $n \in N$ and $n-1<\lambda<n$. For G-L, $\left(\begin{array}{c}q \\ j\end{array}\right)=\frac{(-1)^{j} \Gamma(\lambda+1)}{\Gamma(j+1) \Gamma(\lambda+j-1)}$ and $h$ denotes the finite sampling interval. Assuming zero initial conditions and $X(s)$ is Laplace transformation of $x(t)$, thus its fractional derivative can be written as

$$
L\left[{ }_{0} D_{t}^{\lambda} x(t)\right]=s^{\lambda} X(s)
$$

Keeping the focused objective in mind, the literature presented on the identification and modeling of fractionalorder linear time-invariant (LTI) systems are considered and reviewed. A summary table is included to comprehend the merits of different parameter identification techniques, developed based on fractional-order models for both single and multi inputs systems with or without time delay. The discussion of implementation issues and software tools published in different journals on this topic would help the researchers to grasp the concept easily. In the end, the verification of fractional-order modeling over conventional integer-order modeling will direct the readers with more activity.

\section{Fractional-order Modeling}

System identification and modeling are prerequisites to the exercise of automatic control. Therefore, the chief interest for the identification of any dynamic system lies in its applicability to manipulate and control the system completely based on collected data. Identification of internal parameters is essential for evaluation of system performance and to design robust control for the system under investigation.

Mainly in the last few decades, various techniques have been reported for identifying fractional-order model parameters. Those methods are inculcated using a combination of techniques and different through test signal employed, model type, initial assumptions, assessments, error calculation techniques, and data processing. Fig. 1 shows general ways adopted in the identification of FOM.

Mathematical models can be classified as parametric models and non-parametric models. The parametric model has a specific structure of function of input/output relation or internal states with a finite number of parameters. The former one can be further classified as lower-order and higher- order model while the latter can be described as curve, graph or table. Parametric techniques can be developed using transfer functions or state-space realization. Transfer functions are generally used in SISO systems while state space representation is more generalized and can be used for unstable, non-linear, parameter varying and multivariable systems. The non-parametric model has an infinite number of parameters with no specific mathematical representation. Some popular existing identification parametric model-based methods are operational matrix approach, least square method, instrumental variable method, and step response method.

The operational matrix approach is one of the simplest forms of the fractional model method because of the algebraic approach. Basically, the operational matrix of fractional order integration transforms integral/derivative terms into algebraic matrix multiplications. The operational matrix can be generated using different orthogonal series, for example, block pulse functions [3,4], Legendre wavelet [5], Haar wavelets [6,7], Chebyshev polynomials [8], Taylor series, etc. This method reduces the complexity of identification with higher efficiency. The least square is an old and popular technique for identification. However, the correlation between output and differential input/output term makes least square estimator biased in the presence of noise [9]. This noise can be filtered using state variable filters (SVF). Also, a combination of the instrumental variable with the least square facilitates unbiased estimation [10]. Another approach is a step response-based method where unknown parameters can be estimated using a single step response analysis. It can also be used with the least square method for parameter identification [11].

Same as conventional techniques for integer-order modeling, fractional-order modeling can be developed with commonly used inputs such as step, pulse, random or sine signals. The techniques can be further classified based on input or output signal types whether time or frequency domain. Say for example, step response, least square, relay feedback are the most prominent identification methods in time and frequency domains. Other popular time-domain methods are parameter estimation, subspace, neural network, Kalman filter, operational matrix and, instrumental variable; while Fourier analysis, Laplace transform, frequency response, spectrum analysis, ARMA parameter estimation are well-known frequency-domain techniques. 
As per requirement, identification is carried out either on-line or off-line. For some systems, it is essential to monitor continuously and therefore a recursive identification is required after each measurement. This is also known as real-time identification or on-line identification. In the nonrecursive method, model parameters are updated using previously stored data and estimate the final model parameters using the off-line technique.

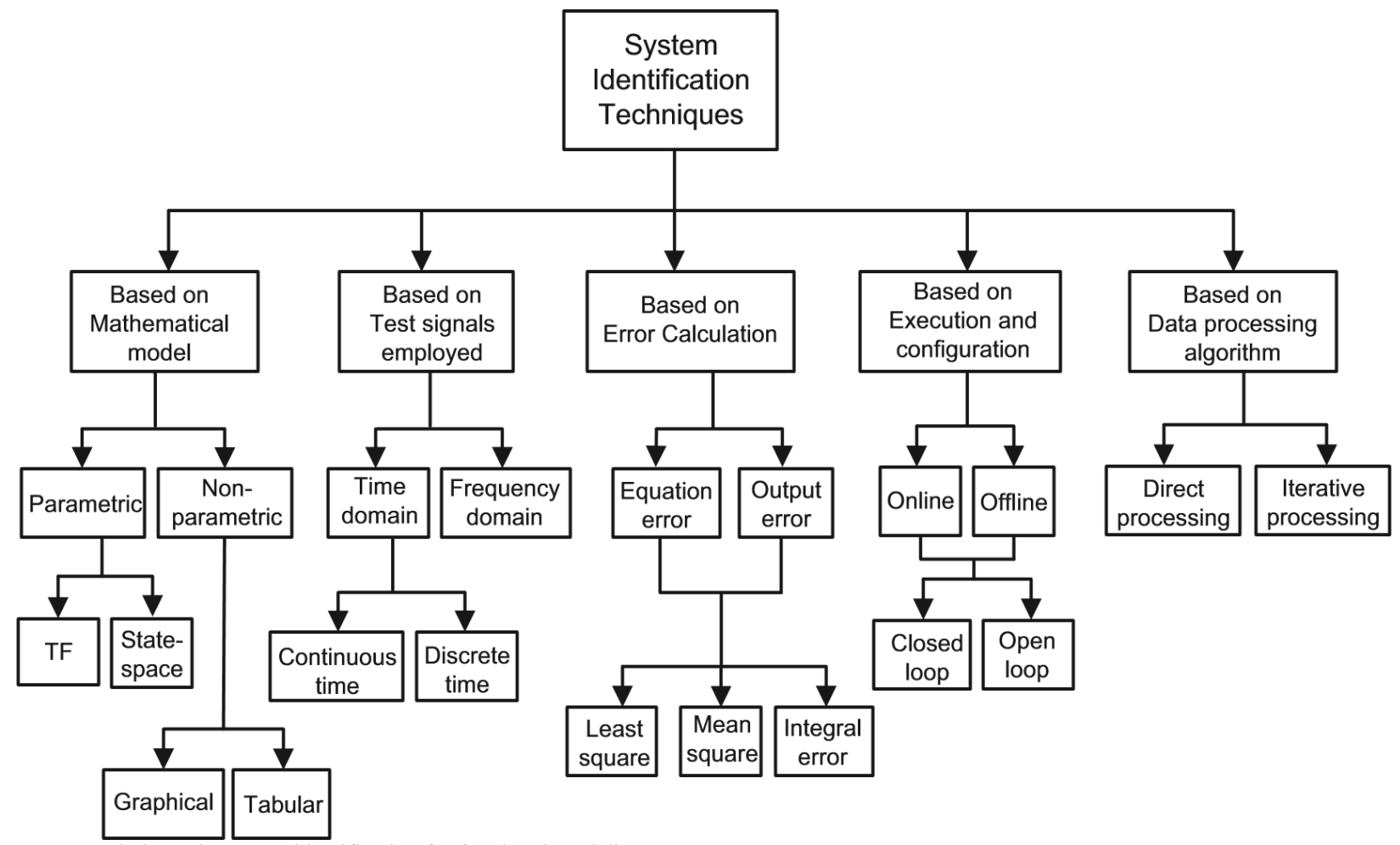

Fig. 1. Techniques in system identification for fractional modeling

Table 2. Identification techniques of fractional-order models

\begin{tabular}{|c|c|c|c|}
\hline Technique & Subclass & Upside & Downside \\
\hline $\begin{array}{l}\text { Operational } \\
\text { matrix } \\
\text { Method }\end{array}$ & 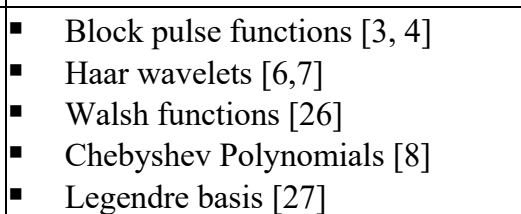 & $\begin{array}{l}\text { An algebraic approach, Less } \\
\text { complexity, Simultaneous } \\
\text { estimation of all the parameters, } \\
\text { Time delay estimation }[4,7,26]\end{array}$ & $\begin{array}{l}\text { Structure of transfer } \\
\text { function should be known } \\
{[3,6]}\end{array}$ \\
\hline $\begin{array}{l}\text { Least square } \\
\text { based state } \\
\text { variable filter } \\
\text { method }\end{array}$ & $\begin{array}{l}\text { - } \quad \text { Instrumental variable (IV) [9] } \\
\text { - } \quad \text { Simplifified Refined IV [10,29] } \\
\text { - } \quad \text { Commensurate order optimization } \\
\text { refined IV (coosrivcf) [30] } \\
\text { - } \quad \text { Error in variables [31] } \\
\quad \text { Bias correction [32] }\end{array}$ & $\begin{array}{l}\text { Time delay estimation [29], } \\
\text { Recursive method [10] }\end{array}$ & $\begin{array}{l}\text { Developed for } \\
\text { commensurate } \\
\text { models, Prior } \\
\text { knowledge required } \\
\text { about unknown } \\
\text { fractional order }\end{array}$ \\
\hline $\begin{array}{l}\text { Relay feedback } \\
\text { method }\end{array}$ & $\begin{array}{l}\text { - Frequency domain method [33] } \\
\text { - Time domain method }\end{array}$ & $\begin{array}{l}\text { Time delay estimation, fast } \\
\text { parameter estimation }\end{array}$ & $\begin{array}{l}\text { High identification } \\
\text { error }\end{array}$ \\
\hline $\begin{array}{l}\text { Step response } \\
\text { method }\end{array}$ & $\begin{array}{l}\text { - } \quad \text { Step response }[34] \\
\text { - } \quad \text { Integral equation }[11,35,36] \\
\text { S-shaped step response }[37,38] \text {, }\end{array}$ & $\begin{array}{l}\text { Time delay estimation, Direct } \\
\text { calculation of parameters [36] }\end{array}$ & $\begin{array}{l}\text { prior knowledge } \\
\text { required }\end{array}$ \\
\hline $\begin{array}{l}\text { Meta heuristic } \\
\text { algorithms }\end{array}$ & 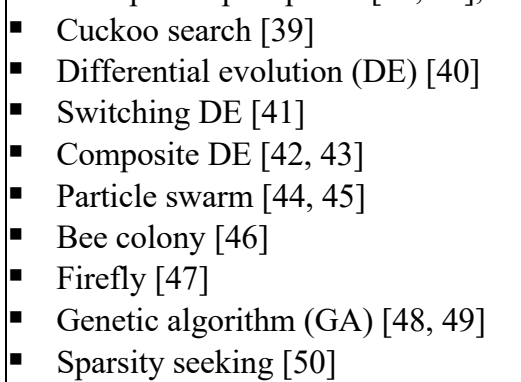 & $\begin{array}{l}\text { Computationally efficient } \\
\text { deterministic optimization, No } \\
\text { prior knowledge required, Fast } \\
\text { convergence }\end{array}$ & $\begin{array}{l}\text { Sometimes } \\
\text { converges at local } \\
\text { minima in GA, } \\
\text { Adverse effects of } \\
\text { noise in DE }\end{array}$ \\
\hline $\begin{array}{l}\text { Frequency } \\
\text { response } \\
\text { method }\end{array}$ & $\begin{array}{l}\text { - Least square }[51,52,53,54,55] \\
\text { - Impulse response }[56,57]\end{array}$ & $\begin{array}{l}\text { Time delay estimation [53], } \\
{[52], \text { No prior knowledge }} \\
{[51]}\end{array}$ & $\begin{array}{l}\text { Developed for } \\
\text { commensurate model } \\
{[60,61,62]}\end{array}$ \\
\hline
\end{tabular}




\begin{tabular}{|c|c|c|c|}
\hline Neural network & $\begin{array}{l}\text { - } \quad \text { Levy's method [58] } \\
\text { - } \quad \text { Set membership [59, 60, 61, 62] } \\
\text { Neural network [63] }\end{array}$ & $\begin{array}{l}\text { Simple architecture, Universal } \\
\text { solution }\end{array}$ & $\begin{array}{l}\text { Black box nature, } \\
\text { Sometimes yields } \\
\text { wrong output with } \\
\text { unknown reasons }\end{array}$ \\
\hline
\end{tabular}

In industry, various systems are available with different dynamic behavior. Due to sensitivity, stability and quality issues, many systems can be operated only in closed-loop configuration under the influence of controller during identification. It is obviously easy to tackle a stable system in open-loop configuration while unstable systems need to be stabilized with the help of an appropriate controller before collecting data for identification. Apart from the exact estimation of model parameters, there is an iterative approach to compute parameters with trails and initial guesses.

In general, model parameters are estimated iteratively by minimization of error between actual and model data. During identification, the error between the actual system and mathematical model is calculated using output or input sampled data. With respect to error derivation, identification can be developed either from output error (OE), input error (IE) or equation error (EE). Among them, OE and EE are most commonly used in literature. As per the authors' knowledge, most OE based techniques are capable of identifying all the system parameters together in a singlestep even without prior knowledge. The EE based techniques may require more than one steps to complete identification and sometimes with prior knowledge of the actual system. The OE based techniques are applicable to even incommensurate models while it is preferred to use EE techniques with commensurate models where all unknown derivative orders have a common measure, or all unknown orders are multiple of least derivative order. Therefore, a complete identification technique can be developed using a set of aforementioned techniques depending on the type of problem and complexity of the model.

\subsection{SISO fractional-order systems}

The concept of arbitrary real-order (fractional-order) for system dynamics was clearly presented in [12] involving fractional-order integrator and differentiator. It was proven for a satisfactory result that it would be better to use fractional-order system instead of a classical integer model. Nearby this year, authors in $[13,14,15,16]$ discussed new ways of system modeling with fractional model. The identification of FOM using continuous order-distributions was described in [17]. Some significant solutions to handle fractional derivatives that helped for associated issues of data processing and overview were given in [18]. An overview of fractional time and frequency domain methods with $\mathrm{OE}$ and EE based models were briefly described in [19]. Also, detailed differences and basics of OE and EE were illustrated in [20]. Identification using the recursive least square method was illustrated in [21]. Different fixed pole-based modeling and simulation techniques were discussed in [22]. The stability analysis of fractional-order systems has been well explained in [23, 24, 25].

It is a good way to understand various techniques with merits and limitations as shown in Table 2. Most of the methods summarized in the table are developed from a parametric model and iterative estimation.

\subsection{MIMO fractional-order systems}

Though less literature have been presented on MIMO (multiinput multi-output) fractional-order systems, identification of such multi-variable systems using fractional-order transfer functions is clearly applicable. The fractional MIMO system identification technique was discussed initially in [64]. The authors described the time-domain state-space method to identify multi-variable system with $\mathrm{OE}$ technique and non-linear programming. The initial condition in the state-space technique was introduced in [65] while authors in [66] illustrated subspace method for MIMO system and verified on robot manipulator. The frequencydomain approach using a genetic algorithm was depicted in [67]. Another state-space based approach was detailed using Guidorzi canonical form in [68] based on OE technique. A two-stage technique, for reduced order approximation based on dominant pole, was derived in [69]. Fractional-order TITO processes were discussed with three different decoupling methods in [70]. A frequency-domain OE based method was illustrated in [71] for MIMO systems. The system identification based CSD method was derived in [72] to design and verify robust MIMO controller for an HD testbed coupled with a spark-ignition engine. In summary, one can see the growth of applications of fractional calculus and such mathematical phenomena describes a real system more accurately than the classical integer models.

\section{Verification}

We have verified some examples in this section to prove the usefulness of fractional-order modeling over conventional integer-order modeling. Both time and frequency domain errors are compared between actual output and estimated output from the models. The fractional-order models perform better for both time-domain plots (step response, sine response, or any random input response) and frequencydomain plots (Nyquist and Bode). In order to verify, let us take two fractional-order transfer functions given by Eq. (4) and Eq. (5).

$$
\begin{aligned}
& p_{1}(s)=\frac{2 s^{0.6}+1}{s^{1.1}+1.5 s^{0.6}+0.5} e^{-0.5 s} \\
& p_{2}(s)=\frac{1}{s^{0.7}+1}
\end{aligned}
$$

The system with time delay was approximated using the Haar wavelet technique, presented recently in [7] and other using block pulse functions presented in [3]. The approximated fractional-order models and integer-order models for both $p_{1}$ and $p_{2}$ are as shown in Table 3 where $\varepsilon_{t}$ depicts time- domain error and $\varepsilon_{f}$ represents frequencydomain error. It is clear from Figs. 2 and 3 that fractionalorder model can approximate any system more precisely due to extra parameter of real order. Also, it is possible to achieve similar performance using low-order dynamics for 
Kajal Kothari, Utkal Mehta and Ravneel PrasadJournal of Engineering Science and Technology Review 12 (5) (2019) 1 - 10

higher order system transfer function. This merit helps to design the controller based on estimated system model.

Table 3. Comparative results of fractional and integer-order models

\begin{tabular}{c|c|c}
\hline $\begin{array}{c}\text { Identified } \\
\text { model }\end{array}$ & Transfer function & Error $\left[\varepsilon_{t}, \varepsilon_{f}\right]$ \\
\hline$p_{1}-$ & $\frac{3.844}{2.052 s^{0.493}+1.776} e^{-0.604 s}$ & {$\left[2.87 \times 10^{-5}, 1.16\right]$} \\
fractional & $\frac{0.723}{0.448 s+0.445} e^{-0.429 s}$ & {$\left[5.40 \times 10^{-3}, 26.84\right]$} \\
$p_{1}$-integer & $\frac{0.979}{0.997 s^{0.716}+0.985}$ & {$\left[4.79 \times 10^{-6}, 2.67\right]$} \\
$p_{2}-$ &
\end{tabular}

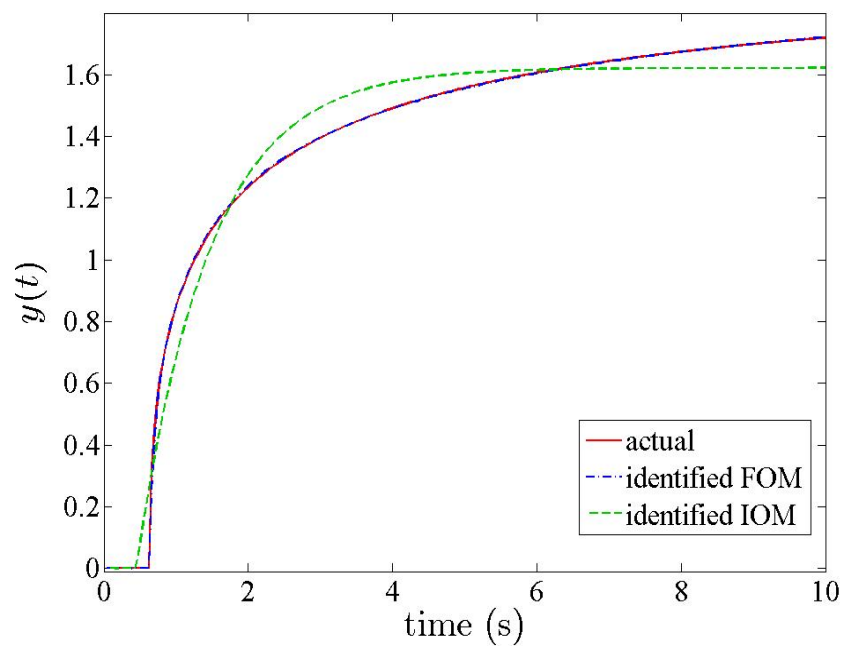

(a)

Fig. 2. (a) For $p_{1}(s)$ : (a) Step responses (b) Nyquist plots

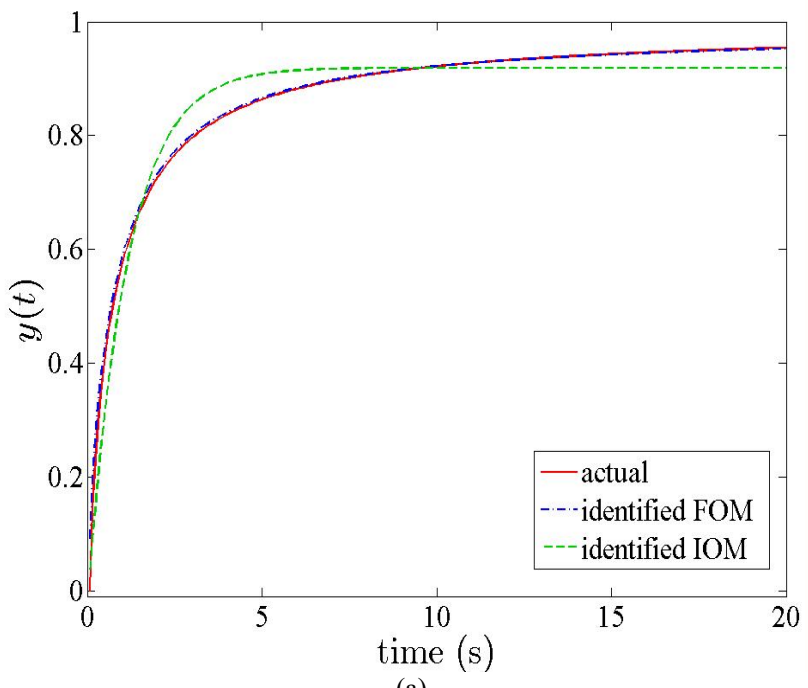

(a)

Fig. 3. (a) For $p_{2}(s)$ : (a) Step responses (b)

Bode plots

Table 4. Identified FOM and IOM for the temperature control process [7]

\begin{tabular}{c|c|c}
\hline Model Type & Identified Model & Error $\varepsilon_{t}$ \\
\hline Fractional & $\frac{20.093}{8.902 s^{1.116}+2.554} e^{-0.501 s}$ & 0.0901 \\
Integer & $\frac{21.009}{8.866 s+2.541} e^{-0.664 s}$ & 0.2359 \\
\hline
\end{tabular}

\begin{tabular}{c|c|c}
$p_{2}-$ & $\frac{1.444}{1.7684 s+1.571}$ & {$\left[1.31 \times 10^{-3}, 33.85\right]$} \\
integer &
\end{tabular}

Another study on real-time temperature process control system was performed to prove the advantage of fractionalorder transfer function model. The Haar wavelet-based identification method [7] was used to identify fractional and integer order model (IOM) parameters. Table 4 shows the identified FOM and IOM models with time-domain estimation errors. Fig. 4 illustrates the actual process output (temperature) with identified fractional and integer models' outputs. Results clearly reveal that the behavior of the actual process is more closely followed by the FOM output.

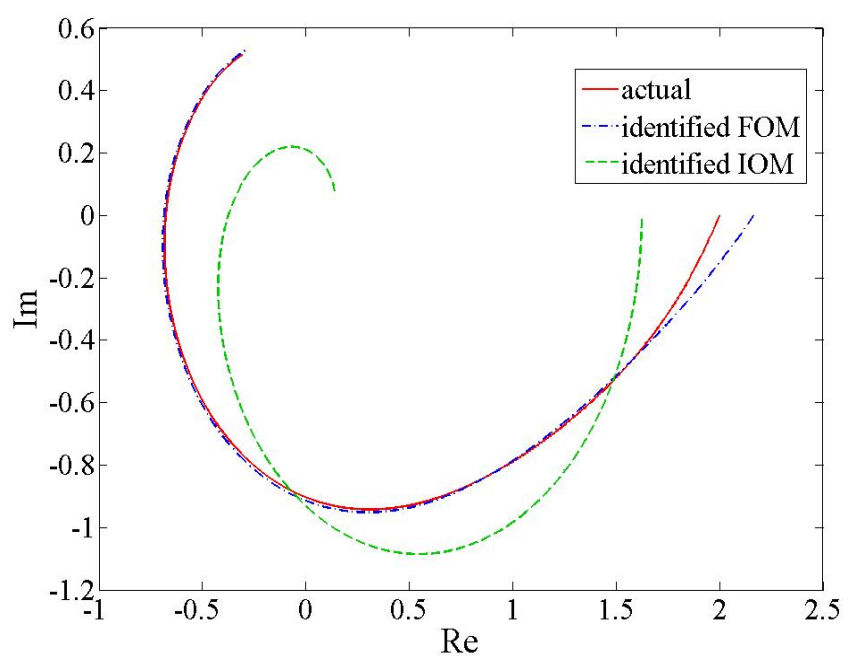

(b)

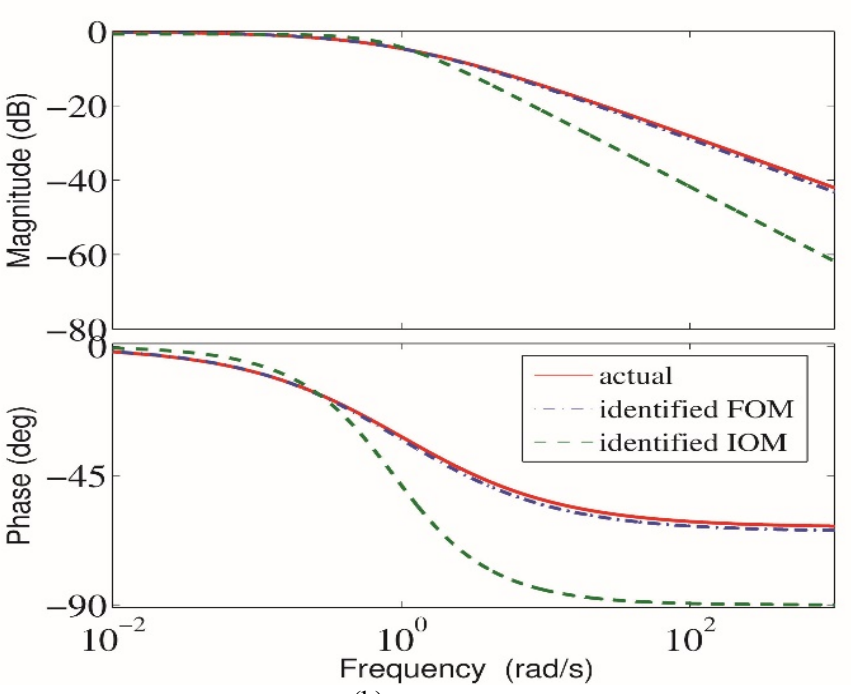

(b)

5. Few more applications towards fractional-domain and challenges

The real systems are generally fractional, whether small or less fractionality. The reason for using the integer-order models, was the lack of solution methods for fractional differential equations. In last ten years, fractional modeling techniques have been applied on various field of science and engineering. Some applications of fractional calculus were discussed briefly in [73]. In particular with fractional-orders, oscillators [74], supercapacitors [75, 76], filters [77], 
thermo-mechanical systems [78], atmospheric dispersion [79], lithium-ion batteries [80, 81, 82, 83], acid-lead battery [84], electrochemical cell [85], polymer electrolyte membrane fuel cell (PEMFC) [86], thermal systems [87, 88, $89,90]$, heat transfer [91], solid-oxide fuel cells [92], viscoelastic material [93], diffusion modeling [94], solid-core magnetic bearing [95], Zener diode [49], permanent magnet synchronous motor [96], electrical circuits [97, 98], magnetic levitation $[99,100,101]$ were shown with a remarkable result. Recently, laboratory prototype of a hydraulic canal modeling and control strategy have been discussed by [102] using fractional-order time delay TITO models. Modeling of two-pool laboratory hydraulic canal was described by [103]. The approximation technique of massive MIMO system was described by [104] to facilitate wireless communications. Such a variety of applications with fractionality consideration have already convinced researchers and given a reason for furthermore investigation.

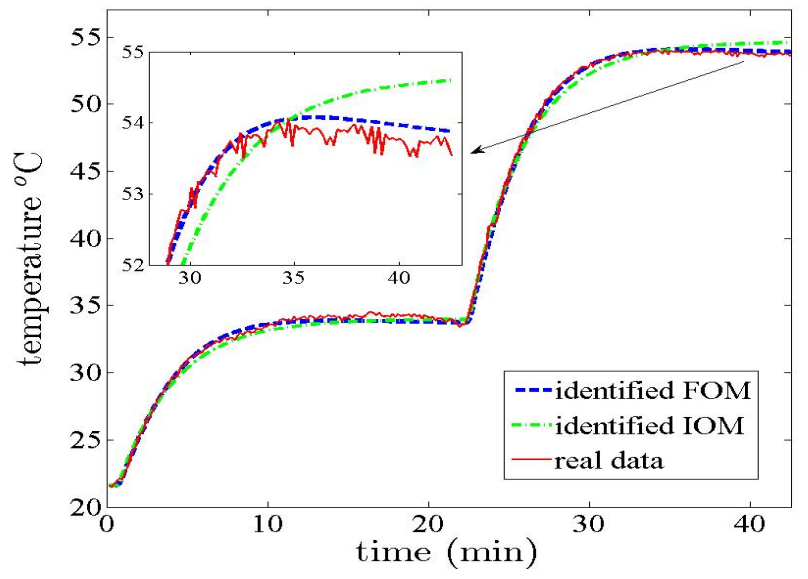

Fig. 4 Temperature process control: Comparison of fractional and integer-order models [7]

\subsection{Implementation Challenges and Software}

As unveiled in the previous section, the fractional approach bestows additional visibility and accuracy. An arbitrary system can be represented by overall lower-order fractional model compared to a conventional model. Thus, reduces the total number of unknown parameters to be estimated which means it lowering the tuning parameters for optimization which ultimately reduces the identification error. Also, a system can be described by a compact expression with the help of fractional model. In spite of various advantages, one has to deal with many challenges in case of fractional model.

In theory, the fractional derivative is non-local and also leads to long memory due to the fact that its value depends on all past values of the function. This facilitates superior accuracy and extra degree of freedom to see between two integer-order derivatives. However, long memory leads to high computational complexity which is elevated even at an impractical level during its implementation. This can be resolved using various approximation techniques [105]. Therefore, real-time implementation of fractional models can be made using approximations which are equivalent to higher-order conventional models [1].

The approximated rational or conventional higher-order transfer function has corresponding pole-zero pairs which ensure stability and minimum phase properties. For continuous implementation, pole-zero pairs should be in the negative real axis of $s$-plane and for discrete implementation, pole-zero pairs should lie within the unit circle of $z$-plane. More number of pole-zero pairs exhibit better and close approximation, but increases the memory requirements and complexity; however, the advent of modern powerful software can easily deal with additional complexity [106].

The fractional or irrational operator can be approximated using continuous and discrete implementation methods. General CFE (continued fraction expansion) [107], Carlson's method [108], Matsuda's method [109], least square method, Chareff's method [110], Oustaloup's method [111] are well known continuous implementation methods while discrete implementation using backward rule and PSE, discrete implementation using backward rule and CFE, discrete implementation using trapezoidal rule and CFE are well known discrete implementation methods.

\subsection{Approximation of $\sqrt{s}$ using various methods:}

The fractional (1/2) derivative can be implemented using various approximation techniques. We have used Carlson's approximation, CFE and Oustaloup's approximation and their magnitude and phase are compared as shown in Fig. 5. The higher order approximated integer transfer function for $\sqrt{s}$, here $5^{\text {th }}$ order integer-order transfer functions, for above mentioned methods can be given as,

$$
\begin{aligned}
& s_{\text {Carlson }} 0.5=\frac{s^{5}+134.3 s^{4}+1072 s^{3}+543.4 s^{2}+20.10 s+0.1259}{15.97 s^{4}+593.2 s^{3}+1080 s^{2}+135.4 s+1} \\
& S_{C F E}^{0.5}=\frac{11 s^{5}+165 s^{4}+462 s^{3}+330 s^{2}+55 s+1}{s^{5}+55 s^{4}+330 s^{3}+462 s^{2}+165 s+11} \\
& s_{\text {Oustaloup }}^{0.5}=\frac{10 s^{5}+298.5 s^{4}+1218 s^{3}+768.5 s^{2}+74.97 s+1}{s^{5}+74.97 s^{4}+768.5 s^{3}+1218 s^{2}+298.5 s+10}
\end{aligned}
$$
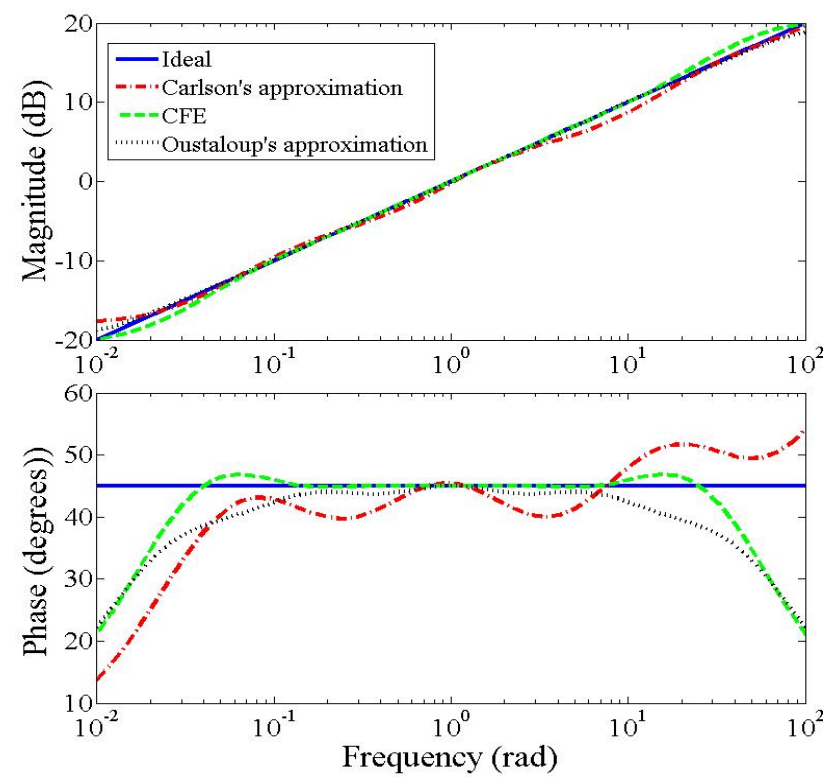

Fig. 5 Approximation of $\sqrt{s}$

\subsection{Realization of fractance devices:}

The fractional-order model and the controller can be implemented using analog and digital realization. The analog realization can be accomplished with the help of analog electrical components while digital realization can be accomplished using digital filters. In the former case, certain approximations may be unrealizable because of higher-order and wider frequency band, therefore, obtained component 
values may become too large or small. In case of digital filters, the difference in the magnitude of coefficient values may lead to loss of computational stability, especially in case of floating-point computations.

The real industrial applications need standalone devices, in that case, the manufacturing cost of fractional devices may not be the same as the conventional counterpart. Additional implementation cost may hinder its real-time realization. Therefore, even though fractional model has been proven technologically superior, industrial adoption for fractional approach requires more analysis [105].

Finally, it is necessary to set up numerical tools in MATLAB for fractional-order transfer functions and controls. Table 5 is listed with available toolboxes with significance. It helps Simulink block for the numerical computation of fractional-order differentiation or integration, together with some features for engineering and science applications for extra degree of controls.

Table 5. System identification toolboxes in fractional-order analysis

\begin{tabular}{|c|c|c|c|}
\hline Year & Toolbox & Developer & Comments \\
\hline 2000 & CRONE & $\begin{array}{l}\text { CRONE team } \\
\text { (Oustaloup, } \\
\text { Melchior, Lanusse, Cois, and } \\
\text { Dancla) }\end{array}$ & $\begin{array}{l}\text { Extended from basic classical to the object-oriented } \\
\text { version, } \\
\text { Implemented for the fractional order MIMO, } \\
\text { Only works with system without time delay. }\end{array}$ \\
\hline 2004 & $\begin{array}{l}\text { Ninteger } \\
\text { (Non-integer) }\end{array}$ & $\begin{array}{l}\text { D. Valerio and } \\
\text { J. Costa }\end{array}$ & $\begin{array}{l}\text { Facilitates three frequency-domain approximations } \\
\text { methods: } \\
\text { CRONE, Carlson's method and Matsuda's method, } \\
\text { Supports at least thirty methods to approximate } \\
\text { fractional operator. }\end{array}$ \\
\hline 2009 & $\begin{array}{l}\text { FOTF } \\
\text { (fractional order transfer } \\
\text { function) }\end{array}$ & $\begin{array}{l}\text { D. Xue and } \\
\text { Y.Q. Chen }\end{array}$ & $\begin{array}{l}\text { Works as an independent transfer function, } \\
\text { Not directly applicable for time varying and MIMO } \\
\text { systems. }\end{array}$ \\
\hline 2011 & FOMCON & $\begin{array}{l}\text { A. Tepljakov, E. Petlenkov and J. } \\
\text { Belikov }\end{array}$ & $\begin{array}{l}\text { More widely adopted in analysis, } \\
\text { Simple and adoptive features in implementation, } \\
\text { Various modules for identification, control, analysis } \\
\text { and testing. }\end{array}$ \\
\hline
\end{tabular}

\section{Summary}

A mini review focuses on fractional-order modeling methods of the recent literatures from a control engineering and system identification perspectives have been summarized in this paper. We briefly discussed the advantageous traits of fractional-order models as an adoptable strategy for system models. Unlike conventional modeling, fractional modeling techniques are not easy to handle due to complex integrodifferential equations of fractional-orders. However, highspeed processors and computers make it possible to deal with this efficient, but complex methodology. Even though fractional modeling demands additional parameters, it allows adjustment of rational orders of derivative. This expands very satisfactory model performance in simulations as well as the same behavior in real-time applications.
Various applications with fractional modeling have been explored which shows the superiority of FC based techniques over its counterpart. The issues discussed in this paper can be useful for new researchers to kick-start the implementation.

Finally, there is a growing demand for fractional-order system modeling because of its potential benefits in daily life applications as revealed in this study. Though some contributions have been discussed so far, there is a huge scope to expand fractional-calculus based approach for multi-variable, time varying, and nonlinear system modeling.

This is an Open Access article distributed under the terms of the Creative Commons Attribution License

\section{References}

[1] Monje C. A., Chen Y., Vinagre B. M., Xue D., Feliu-Batlle V., Fractional-order Systems and Controls, Springer-Verlag London, 2010.

[2] Petras I., Fractional-order Nonlinear Systems: Modeling, Analysis and Simulation, Higher Education Press, Beijing and Springer-Verlag Berlin Heidelberg, 2011.

[3] Tang Y., Liu H., Wang W., Lian Q., Guan X., Parameter identification of fractional order systems using block pulse functions, Signal Processing 107 (2015), 272-281.

[4] Tang Y., Li N., Liu M., Lu Y., Wang W., Identification of fractional-order systems with time delays using block pulse functions, Mechanical Systems and Signal Processing 91 (2017), 382-394.

[5] Kashkari B. S., Syam M. I., Fractional-order Legendre operational matrix of fractional integration for solving the Riccati equation with fractional order, Applied Mathematics and Computation 290 (2016), 281-291.

[6] Li Y., Meng X., Zheng B., Ding Y., Parameter identification of fractional order linear system based on Haar wavelet operational matrix, ISA Transactions 59 (2015), 79-84.

[7] Kothari K, Mehta U., Vanualailai J., A novel approach of fractional-order time delay system modeling based on Haar wavelet, ISA Transactions 80 (2018), 371-380.

[8] Bhrawy A., Alofi A., The operational matrix of fractional integration for shifted Chebyshev polynomials, Applied Mathematics Letters 26 (2013), 1, 25-31.

[9] Cois O., Oustaloup A., Poinot T., Battaglia J.-L., Fractional state variable filter for system identification by fractional model, European Control Conference (ECC), 2001, 2481-2486. 
[10] Malti R., Victor S., Oustaloup A., Garnier H., An optimal instrumental variable method for continuous-time fractional model identification, Proceedings of the 17 th World Congress The International Federation of Automatic Control, 2008, 1437914389.

[11] Ahmed S., Parameter and delay estimation of fractional order models from step response, IFAC-PapersOnLine 46 (2015), 942 947

[12] Podlubny I., Fractional-order systems and $\mathrm{PI}^{\lambda} \mathrm{D}^{\mu}$-controllers, IEEE Transactions on Automatic Control 44 (1999), 1, 208-214.

[13] Lay L.L., Identification fréquentielle et temporelle par modéle non entier, Ph.D. thesis, Université Bordeaux I,Talence (1998).

[14] Lin J., Modélisation et identication de systèmes $d$ ordre non entier, Ph.D. thesis, Université de Poitiers, France (2001)

[15] Cois O., Systèmes linéaires non entiers et identication par modèle non entier: application en thermique, Ph.D. thesis, Université Bordeaux 1, Talence (2002).

[16] Aoun M., Systèmes linéaires non entiers et identication par modèle non entier: application en thermique, Ph.D. thesis, Université Bordeaux 1, Talence (2002).

[17] Hartley T. T., Lorenzo C. F., Fractional-order system identification based on continuous order-distributions, Signal Processing 83 (2003), 11, 2287-2300.

[18] Aoun M., Malti R., Levron F., Oustaloup A., Numerical simulations of fractional systems: An overview of existing methods and improvements, Nonlinear Dynamics 38 (2004), 117 131.

[19] Malti R., Aoun M., Sabatier J., Oustaloup A., Tutorial on system identification using fractional differentiation models, in: 14th IFAC Symposium on System Identification, 2006, 606-611.

[20] Malti R., Victor S., Oustaloup A., Advances in system identification using fractional models, Journal of Computational and Nonlinear Dynamics 3 (2008), 021401.1-021401.7.

[21] Idiou D., Charef A., Djouambi A., Linear fractional order system identification using adjustable fractional order differentiator, IET Signal Processing 891 (2014), 398-409.

[22] Wei Y., Wang J., Liu T., Wang Y., Fixed pole-based modeling and simulation schemes for fractional order systems, ISA Transactions, 84 (2019), 43-54.

[23] Moze M., Sabatier J., Oustaloup A., LMI Tools for stability analysis of fractional systems, in: 5 th International Conference on Multibody Systems, Nonlinear Dynamics, and Control, 2005, 1611-1619.

[24] Matignon D., Stability properties for generalized fractional differential systems, ESAIM: Proc. 5 (1998), 145-158.

[25] Malti R., Moreau X., Khemane F., Oustaloup A., Stability and resonance conditions of elementary fractional transfer functions, Automatica, 47 (2011), 11, 2462-2467.

[26] Kothari K., Mehta U., Vanualailai J., Fractional-order models of time delay systems using Walsh operational matrices, in: 2018 15 th International Conference on Control, Automation, Robotics and Vision (ICARCV), 2018, 1555-1560.

[27] Ghanbari M., Haeri M., Parametric identification of fractionalorder systems using a fractional Legendre basis, Proceedings of the Institution of Mechanical Engineers, Part I: Journal of Systems and Control Engineering 224 (2010), 3, 261-274

[28] Narang A., Shah S., Chen T., Continuous-time model identification of fractional order models with time delays, IET Control Theory Appl. 5 (2011), 7, 900-912.

[29] Victor S., Malti R., Garnier H., Oustaloup A., Parameter and differentiation order estimation in fractional models, Automatica 49 (2013), 926-935.

[30] Victor S., Malti R., Oustaloup A., Instrumental variable method with optimal fractional differentiation order for continuous-time system identification, Proceedings of the 15th IFAC Symposium on System Identification 2009, 904-909.

[31] Chetoui M., Malti R., Thomassin M., Aoun M., Najar S., Oustaloup A., Abdelkrim M. N., EIV methods for system identification with fractional models, IFAC Proceedings Volumes 45 (2012), 16, 1641-1646.

[32] Yakoub Z., Chetoui M., Amairi M., Aoun M., A bias correction method for fractional closed-loop system identification, Journal of Process Control 33 (2015), 25-36.

[33] Li Z., Chen Y., Identification of linear fractional order systems using the relay feedback approach, in: 2014 American Control Conference, 2014, 3704-3709.

[34] Nie Z., Wang Q., Liu R., Lan Y., Identification and PID control for a class of delay fractional-order systems, IEEE/CAA Journal of Automatica Sinica 3(2016), 4, 463-476.
[35] Tavakoli-Kakhki M., Tavazoei M. S., Mesbahi A., Parameter and order estimation from noisy step response data, IFAC Proceedings Volumes 46 (2013), 1, 492-497, 6th IFAC Workshop on Fractional Differentiation and Its Applications.

[36] Tavakoli-Kakhki M., Tavazoei M. S., Estimation of the order and parameters of a fractional order model from a noisy step response data, Journal of Dynamic Systems, Measurement, and Control 136 (2014), 3, 031020.1-031020.6.

[37] Tavakoli-Kakhki M., Haeri M., Tavazoei M. S., Simple fractional order model structures and their applications in control system design, European Journal of Control 16 (2010), 6, 680-694.

[38] Malek H., Luo Y., Chen Y., Identification and tuning fractional order proportional integral controllers for time delayed systems with a fractional pole, Mechatronics 23 (2013),7, 746-754.

[39] Kumar M., Rawat T. K., Optimal design of FIR fractional order differentiator using cuckoo search algorithm, Expert Systems with Applications 42 (2015), 7, 3433-3449.

[40] Tang Y., Zhang X., Hua C., Li L., Yang Y., Parameter identification of commensurate fractional-order chaotic system via differential evolution, Physics Letters A 376 (2012), 457-464.

[41] Zhu W., Fang J. A, Tang Y., Zhang W., Xu Y., Identification of fractional-order systems via a switching differential evolution subject to noise perturbations, Physics Letters A, 376 (45) (2012), 3113- 3120 .

[42] Du W., Miao Q., Tong L., Tang Y., Identification of fractionalorder systems with unknown initial values and structure, Physics Letters A, 381 (2017),23, 1943-1949.

[43] Du W., Tong L., Tang Y., Metaheuristic optimization-based identification of fractional-order systems under stable distribution noises, Physics Letters A, 382 (2018), 34, 2313-2320.

[44] Mansouri R., Bettayeb M., Djamah T., Djennoune S., Vector fitting fractional system identification using particle swarm optimization, Applied Mathematics and Computation, 206 (2008), 2, 510-520, includes Special issue on Modeling, Simulation, and Applied Optimization (ICMSAO-07.

[45] Gupta R., Gairola S., Diwiedi S., Fractional order system identification and controller design using PSO, in: 2014 Innovative Applications of Computational Intelligence on Power, Energy and Controls with their impact on Humanity (CIPECH), 2014, 149-153.

[46] Hu W., Yu Y., Gu W., Parameter estimation of fractional-order arbitrary dimensional hyper chaotic systems via a hybrid adaptive artificial bee colony algorithm with simulated annealing algorithm, Engineering Applications of Artificial Intelligence 68 (2018), 172-191

[47] Mousavi Y., Alfi A., Fractional calculus-based firefly algorithm applied to parameter estimation of chaotic systems, Chaos, Solitons \& Fractals 114 (2018), 202-215.

[48] Othman M. Z., Al-Sabawi E. A., Fractional order system identification based on genetic algorithms, Journal of Engineering Science and Technology 8 (2013), 6, 713-722.

[49] Hao D., Li D., Liao Y., Parameter identification of modified fractional Zener model for thermo-rheological materials, Journal of Non-Crystalline Solids 409 (2015), 106- 119.

[50] Varanasi S. K., Jampana P., Parameter estimation and model order identification of LTI systems, IFAC-PapersOnLine 49 (2016), 7, 1002-1007, 11th IFAC Symposium on Dynamics and Control of Process Systems Including Biosystems DYCOPSCAB 2016.

[51] Gehring N., Rudolph J., An algebraic approach to the identification of linear systems with fractional derivatives, IFAC PapersOnLine 50 (2017), 1, 6214-6219.

[52] Das S., Molla N. U., Pan I., Pakhira A., Gupta A., Online identification of fractional order models with time delay: An experimental study, in: International Conference on Communication and Industrial Application, 2011, 1-5.

[53] Peng C., Li W., Wang Y., Frequency domain identification of fractional order time delay systems, in: Chinese Control and Decision Conference, 2010, 2635-2638.

[54] Li D., Liu L., Song T., Shen D., On arbitrary fractional system identification in frequency domain, IFAC-PapersOnLine 48 (2015), 28, 1421-1426.

[55] Adams J. L., Hartley T. T., Lorenzo C. F., Fractional-order system identification using complex order-distributions, In IFAC Proceedings Volumes 39 (2006), 11, 200-205.

[56] Chen Q., Mai W., Zhang L., Mi W., System identification by discrete rational atoms, Automatica 56 (2015), 53-59. 
[57] Hagg P., Schoukens J., Gevers M., Hjalmarsson H., The transient impulse response modeling method for non-parametric system identification, Automatica 68 (2016), 314-328.

[58] D. Valerio, I. Tejado, Identifying a non-commensurable fractional transfer function from a frequency response, Signal Processing 107 (2015) $254-264$

[59] Malti R. R., Raïssi T., Thomassin M., Khemane F., Set membership parameter estimation of fractional models based on bounded frequency domain data, Communications in Nonlinear Science and Numerical Simulation 15 (2010), 4, 927-938.

[60] Khemane F., Malti R., Raïssi T., Moreau X., Robust estimation of fractional models in the frequency domain using set membership methods, Signal Processing 92 (2012), 7, 15911601.

[61] Amairi M., Recursive set-membership parameter estimation using fractional model, Circuits Syst. Signal Process. 34 (2015), 12, 3757-3788

[62] Hamdi S. E., Amairi M., Aoun M., Recursive set-membership parameter estimation of fractional systems using orthotopic approach, Transactions of the Institute of Measurement and Control 40 (2018), 15, 4185-4197.

[63] Gu Y., Yu Y., Wang H., Synchronization based parameter estimation of fractional-order neural networks, Physica A: Statistical Mechanics and its Applications 483 (2017) 351-361.

[64] Thomassin M., Malti R., Multivariable identification of continuous-time fractional system, Proceedings of the ASME Design Engineering Technical Conference, San Diego, USA, 2009, 1-9.

[65] Mansouri R., Bettayeb M., Djennoune S., Multivariable fractional system approximation with initial conditions using integral state space representation, Computers \& Mathematics with Applications 59 (2010), 5, 1842-1851.

[66] Behzad H., Shandiz H. T., Noori A., Abrishami T., Robot identification using fractional subspace method, in: The 2nd International Conference on Control, Instrumentation and Automation, 2011, 1193-1199.

[67] Liao Z., Peng C., Wang Y., A frequency-domain identification algorithm for MIMO fractional order systems with time-delay in state, in: Manufacturing Science and Technology, ICMST2011, Vol. 383 of Advanced Materials Research, Trans Tech Publications, 2012, 4397-4404.

[68] Djamah T., Bettayeb M., Djennoune S., Identification of multivariable fractional order systems, Asian Journal of Control, 15 (2013), 2, 1-10

[69] Khanra M., Pal J., Biswas K., Reduced order approximation of MIMO fractional order systems, IEEE Journal on Emerging and Selected Topics in Circuits and Systems, 3 (2013), 451-458.

[70] Li Z., Chen Y., Ideal, simplified and inverted decoupling of fractional order TITO processes, IFAC Proceedings Volumes 47 (2014), 3, 2897-2902.

[71] Ivanova E., Malti R., Moreau X., Frequency-domain subspace system identification with fractional differentiation models, in: 2014 IEEE/ASME 10th International Conference on Mechatronic and Embedded Systems and Applications (MESA), 2014, 1-6.

[72] Lanusse P., Gruel D. N., Lamara A., Lesobre A., Wang X., Chamaillard Y., Oustaloup A., Development of a fractional order-based MIMO controller for high dynamic engine testbeds, Control Engineering Practice, 56 (2016), 174-189.

[73] Dalir M., Bashour M., Applications of fractional calculus, Applied Mathematical Sciences 4 (2010), 21, 1021-1032.

[74] Radwan A. G., Elwakil A. S., Soliman A. M., Fractional-order sinusoidal oscillators: Design procedure and practical examples, IEEE Transactions on Circuits and Systems I: Regular Papers 55 (2008), 7, 2051-2063.

[75] Freeborn T. J., Maundy B., Elwakil A. S., Measurement of supercapacitor fractional-order model parameters from voltageexcited step response, IEEE Journal on Emerging and Selected Topics in Circuits and Systems (2013), 3, 367-376.

[76] Prasad R., Kothari K. and Mehta U., Flexible fractional supercapacitor model analyzed in time domain, IEEE Access, 7 (2019), 122626-122633.

[77] Mahata S., Saha S. K., Kar R., Mandal D., Optimal design of fractional order low pass Butterworth filter with accurate magnitude response, Digital Signal Processing, 72 (2018), 96114

[78] Lei D., Liang Y., Xiao R., A fractional model with parallel fractional Maxwell elements for amorphous thermoplastics, Physica A: Statistical Mechanics and its Applications, 490 (2018), 465-475.
[79] Goulart A., Lazo M., Suarez J., Moreira D., Fractional derivative models for atmospheric dispersion of pollutants, Physica A: Statistical Mechanics and its Applications 477 (2017), 9-19.

[80] Wang B., Li S. E., Peng H., Liu Z., Fractional-order modeling and parameter identification for lithium-ion batteries, Journal of Power Sources, 293 (2015), 151-161.

[81] Jiang Y., Xia B., Zhao X., Nguyen T., Mi C., de Callafon R. A., Identification of fractional differential models for lithium-ion polymer battery dynamics, IFAC PapersOnLine, 50 (2017), 1, 405-410

[82] Hu M., Li Y., Li S., Fu C., Qin D., Li Z., Lithium-ion battery modeling and parameter identification based on fractional theory, Energy, 165 (2018), 153-163.

[83] Lu X., Li H., Chen N., An indicator for the electrode aging of lithium-ion batteries using a fractional variable order model, Electrochimica Acta, 299 (2019), 378-387.

[84] Sabatier J., Cugnet M., Laruelle S., Grugeon S., Sahut B., Oustaloup A., Tarascon J., A fractional order model for lead-acid battery crankability estimation, Nonlinear Science and Numerical Simulation, 15 (2010), 5, 1308-1317.

[85] Eddine A. N., Huard B., Gabano J.-D., Poinot T., Thomas A., Martemianov S., Time domain diffusion parameters identification of electrochemical impedance models using fractional order system, IFAC-PapersOnLine 51 (2018), 15, 377- 382.

[86] Taleb M. A., Béthoux O., Godoy E., Identification of a PEMFC fractional order model, International Journal of Hydrogen Energy, 42 (2017), 2, 1499-1509.

[87] Gabano J.-D., Poinot T., Kanoun H., Identification of a thermal system using continuous linear parameter-varying fractional modeling, IET Control Theory and Applications 5 (2011), 7, 889899.

[88] Gabano J.-D., Poinot T., Fractional modeling and identification of thermal systems, Signal Processing 91 (2011), 3, 531-541.

[89] Gabano J.-D., Poinot T., Fractional identification algorithms applied to thermal parameter estimation, Proceedings of the 15 th IFAC Symposium on System Identification 2009, 1316-1321.

[90] Wang D., Wang X., Han P., Identification of thermal process using fractional order transfer function based on intelligent optimization, in: Proceedings of 2010 IEEE/ASME International Conference on Mechatronic and Embedded Systems and Applications, 2010, 498-503.

[91] Benchellal A., Poinot T., Trigeassou J.-C., Approximation and identification of diffusive interfaces by fractional models, Signal processing, 86 (2006), 2712-2727.

[92] Dolenc B., Nusev G., Subotic V., Hochenauer C., Gehring N., Juricic D., Boškoski P., Fractional-order model identification for state of health assessment of solid-oxide fuel cells, IFACPapersOnLine, 51 (2018), 24, 849-854.

[93] Schmidt A., Gaul L., Application of fractional calculus to viscoelastically damped structures in the finite element method, in: International Conference on Structural Dynamics Modeling, 2002, 297-306.

[94] Sierociuk D., Skovranek T., Macias M., Podlubny I., Petras I., Dzielinski A., Ziubinski P., Diffusion process modeling by using fractional-order models, Applied Mathematics and Computation, 257 (2015), 2-11.

[95] Zhong J., Li L., Fractional-order system identification and proportional derivative control of a solid-core magnetic bearing, ISA Transactions 53 (2014), 4, 1232-1242.

[96] Yousri D., Allam D., Eteiba M., Chapter 18 - parameters identification of fractional order permanent magnet synchronous motor models using chaotic metaheuristic algorithms, in: Mathematical Techniques of Fractional Order Systems, Elsevier, 2018, 529-558.

[97] Gomez-Aguilar J. F., Yepez-Martinez H., Escobar-Jimenez R.F., Astorga Zaragoza C., Reyes-Reyes J., Analytical and numerical solutions of electrical circuits described by fractional derivatives, Applied Mathematical Modeling 40 (2016), 21, 9079-9094.

[98] Morales-Delgado V., Gómez-Aguilar J.F., Taneco-Hernandez M., Analytical solutions of electrical circuits described by fractional conformable derivatives in Liouville-Caputo sense, AEU-International Journal of Electronics and Communications 85 (2018), 108-117.

[99] S. K. Swain, D. Sain, S. K. Mishra, S. Ghosh, Real time implementation of fractional order PID controllers for a magnetic levitation plant, AEU - International Journal of Electronics and Communications 78 (2017) $141-156$.

[100] Pandey S., Dwivedi P., Junghare A., A novel 2-DOF fractionalorder $\mathrm{PI}^{\lambda} \mathrm{D}^{\mu}$ controller with inherent anti-windup capability for a 
Kajal Kothari, Utkal Mehta and Ravneel PrasadJournal of Engineering Science and Technology Review 12 (6) (2019) 1 - 10

magnetic levitation system, AEU-International Journal of Electronics and Communications 79 (2017), 158-171.

[101] Kothari K., Mehta U., Singh N., Practical test for closed-loop identification and control on magnetic levitation system: A fractional-order approach, in: 2018 15th International Conference on Control, Automation, Robotics and Vision (ICARCV), 2018, 1805-1810.

[102] San-Millan A., Feliu-Talegon D., Feliu-Batlle V., Rivas-Perez R., On the modeling and control of a laboratory prototype of a hydraulic canal based on a TITO fractional-order model, Entropy 201719 (2017), 8, 401

[103] Feliu-Batlle V., San-Millán A., Feliu-Talegón D., Rivas-Pérez R., Multivariable fractional-order model of a laboratory hydraulic canal with two pools, in: 2017 4th International Conference on Control, Decision and Information Technologies (CoDIT), 2017, 0450-0455.

[104] Lupupa M., Hadjiloucas S., Fractional-order system identification in massive MIMO systems, Journal of Physics: Conference Series, 1065 (2018), 1-4
[105] Tepljakov A., Alagoz B. B., Yeroglu C., Gonzalez E., Hossein Nia S. H., Petlenkov E., FOPID controllers and their industrial applications: A survey, IFAC-PapersOnLine 51 (2018), 4, 25-30.

[106] A. Tepljakov, Fractional-order modeling and control of dynamic systems, Springer International Publishing, 2017.

[107] Roy S. C. D., On the realization of a constant-argument immittance or fractional operator, IEEE Transactions on Circuit Theory, 14 (1967), 3, 264-274.

[108] Carlson G. E., Halijak C. A., Approximation of fractional capacitors by a regular Newton process, IRE Transactions on Circuit Theory, 11 (1964), 2, 210-213.

[109] Matsuda K. and Fujii H., Optimized wave-absorbing control: Analytical and experimental results. Journal of Guidance, Control, and Dynamics, 16 (1993), 6, 1146-1153.

[110] Ovivier D., Approximating irrational transfer functions using Lagrange interpolation formula, IEE Proceedings D - Control Theory and Applications, 139 (1992), 1, 9-13.

[111] Oustaloup A., Levron F., Mathieu B., Nanot F. M., Frequencyband complex non- integer differentiator: Characterization and synthesis, IEEE Trans. on Circuits \& Systems I: Fundamental Theory and Applications, 47 (2000), 1, 25-39. 